\title{
RETRACTED ARTICLE: Image-based forgery detection using big data clustering
}

\author{
Chao Xiong ${ }^{1} \cdot$ Ju Zhu $^{2} \cdot$ Yuan $\mathrm{Li}^{1} \cdot$ Ruxi Xiang ${ }^{1}$
}

Received: 14 December 2017 / Revised: 18 December 2017 / Accepted: 20 December 2017 /

Published online: 4 January 2018

(C) Springer Science+Business Media, LLC, part of Springer Nature 2018

This article is retracted at the request of Editor-in-Chief because its content has been duplicated from an unpublished manuscript authored by Osamah M. Al-Qershi and Bee Ee Khoo without permission. Author Chao Xiong does not agree to this retraction. Authors Yuan Li, Ruxi Xiang, and Ju Zhu have not responded to any correspondence from the editor or publisher about this retraction.

The online version of this article contains the full text of the retracted article as electronic supplementary material.

Electronic supplementary material The online version of this article (https://doi.org/10.1007/s11042-0175555-3) contains supplementary material, which is available to authorized users.

\section{Chao Xiong}

xiongchaoxc88@163.com

1 School of Electrical and Photoelectronic Engineering, Changzhou Institute of Technology, Changzhou, Jiangsu Province 213032, China

2 The 41st Institute of China Electronics Technology Group Corporation, Qingdao, China 